\title{
Theoretical Studies of Reactivity Descriptors, Electronic and Nonlinear Optical Properties of Multifunctionalized Fullerene Ylide With Acetylsalicylic Acid.
}

Christian Aimé Njeumen ( $\nabla$ njeumenac@gmail.com )

University of Yaounde I: Universite de Yaounde I

\section{Geh Wilson Ejuh}

University of Dschang: Universite de Dschang

Yannick Tadjouteu Assatse

University of Yaounde I: Universite de Yaounde I

Richard Arnaud Yossa Kamsi

University of Yaounde I: Universite de Yaounde I

Jean Marie Bienvenu Ndjaka

University of Yaounde I: Universite de Yaounde I

\section{Research Article}

Keywords: Multifunctionalization, Fullerene ylide, Nanostructures, Acetylsalicylic acid.

Posted Date: March 22nd, 2021

DOI: https://doi.org/10.21203/rs.3.rs-278527/v1

License: (c) (i) This work is licensed under a Creative Commons Attribution 4.0 International License.

Read Full License 


\title{
Theoretical studies of reactivity descriptors, electronic and nonlinear optical properties of multifunctionalized fullerene ylide with acetylsalicylic acid.
}

Christian Aimé Njeumen ${ }^{\mathrm{a},}$, Geh Wilson Ejuh ${ }^{\mathrm{b}, \mathrm{c}}$, Yannick Tadjouteu Assatse ${ }^{\mathrm{a}}$, Richard Arnaud Yossa Kamsia ${ }^{\mathrm{a}}$, Jean Marie Bienvenu Ndjaka ${ }^{\mathrm{a}}$.

${ }^{a}$ University of Yaoundé I, Faculty of Science, Department of Physics, Materials Science Laboratory, P. O. Box 812 Yaoundé, Cameroon

${ }^{b}$ University of Dschang, IUT Bandjoun, Department of General and Scientific Studies, P. O. Box 134 Bandjoun, Cameroon

${ }^{c}$ University of Bamenda, National Higher Polytechnic Institute, Department of Electrical and Engineering, P. O. Box 39 Bambili, Cameroon

* Corresponding author.

Name: Christian Aimé Njeumen,

E-mail address: njeumenac@gmail.com

\begin{abstract}
DFT calculations were performed to study the nanostructures obtained by the multifunctionalization of one and two acetylsalicylic acid radicals on fullerene ylide. The increase in the number of aspirin molecules functionalized on fullerene ylide increases the energy stability of the formed nanostructures. The analysis of the vibrational spectra of these nanostructures shows that the formed systems are stable and present some vibrational modes in accordance with the experimental data. The degree of solubility and polarity of these nanostructures increases with the number of functionalized molecules. Multifunctionalization considerably improves the nonlinear optical properties of the modeled nanostructures. With functionalization of isolated aspirin molecule, the electronic properties are very improved, not too much passing to multifunctionalization. The formed nanostructures are soft, more electrophilic and more reactive than the aspirin molecule, but with multifunctionalization the charge transfer decreases.
\end{abstract}

Keywords: Multifunctionalization; Fullerene ylide; Nanostructures; Acetylsalicylic acid. 


\section{Introduction}

Fullerenes as well as carbon nanotubes, graphenes, sp-sp2 graphynes and many other synthetic allotropic forms are the latest discoveries in the family of carbonaceous elements [1]. All these carbon nanotropes are now widely used and have opened up a wide range of applications in the field of nanotechnology and nanomedicine. Experimental techniques such as chemical vapor deposition and high-temperature combustion have been developed for the synthesis of these nanotropes [2]. In recent work, these nanomaterials have had multiple applications, such as targeted drug delivery, magnetic resonance imaging (MRI), optical imaging, photodynamic therapy and miniaturization of electronic components [3-5]. For example, non-steroidal anti-inflammatory drugs (NSAIDs) are widely used in therapy for their antipyretic, analgesic or anti-inflammatory effects [6]; excessive use can cause gastrointestinal problems, including irritation, bleeding and ulceration [7]. Mainly for acetylsalicylic acid (ASA), better known as aspirin, which is one of the most widely used drugs in the world. Although many pharmaceutical investigations show that aspirin can be used as an antithrombotic agent, it may help treat coronary heart and Alzheimer's diseases, and possibly have cancer prevention properties $[8,9]$. Therefore, further studies on targeting acetylsalicylic acid are required to avoid his bad effects in the body, why we think of transport of it by fullerenes as nanovectors. In order to improve the stability, solubility and load-bearing capacity of the drug, we have chosen to multifunctionalize acetylsalicylic acid molecules on fullerene ylide, as demonstrated by recent studies. Gallo et al. [10] have reported on research in which they showed the DFT study of functionalized carbon nanotubes and fullerenes as nanovectors for drug delivery of antitubercular compounds. Prow et al. [11] have worked on nano- and micro-particles for skin drug delivery. Zhang et al. [12] have experimentally showed the synthesis of C60 fullerene with the end-capped polystyrene, while Wang et al. [13] have investigated the novel cycloaddition reaction of fullerene C60 with carbonyl ylides generated from epoxides.

For this work, we used the Bingel reaction [14], which consists in the deprotonation by $\mathrm{NaH}$ of a $\alpha$-bromomalonate on the carbon sphere of the fullerene. Then, the anion generated on the fullerene will perform an intramolecular nucleophilic substitution to give cyclopropane and the mono-additional fullerene ylide derivative. After synthesis of the nanovectors, covalent functionalization of aspirin drug molecules can be performed experimentally by grafting, hydrogenolysis or cyclopropriation $[15,16]$.

The aim of this work is to improve the targeted transfer of acetylsalicylic acid and to form new nanostructures for nanotechnology applications. To do so, the global reactivity descriptors, structural, nonlinear, electronic and optical properties of these molecular systems have been studied. All this research was carried out by DFT studies.

\section{Methodology}

Our systems were consisted of fullerene (FULL) C60 previously functionalized to carbonyl ylide $(\mathrm{C} 3 \mathrm{H} 2 \mathrm{O} 4)$ by 1,3-dipolar cycloaddition to give fullerene ylide (FULL(C60)fC3H2O4) as a nanovector. They were then bonded to the radicals of one aspirin molecule (C9H8O4) and two aspirin molecules $(\mathrm{C} 18 \mathrm{H} 16 \mathrm{O} 8)$ to form respectively 
nanostructure A (FULL(C60)fC3HO4-C9H7O4) and nanostructure B (FULL(C60)fC3O4C18H14O8) according to equations (1) and (2) :

$$
\begin{aligned}
& \mathrm{ASA}(\mathrm{C} 9 \mathrm{H} 804)+\mathrm{FULL}(\mathrm{C60}) \mathrm{fC} 3 \mathrm{H} 2 \mathrm{O} 4 \rightarrow \mathrm{A}(\mathrm{FULL}(\mathrm{C} 60) \mathrm{fC} 3 \mathrm{HO} 4-\mathrm{C} 9 \mathrm{H} 7 \mathrm{O} 4)+\mathrm{H}_{2} \\
& \mathrm{ASA}(\mathrm{C} 9 \mathrm{H} 804)+\mathrm{A}(\mathrm{FULL}(\mathrm{C} 60) \mathrm{fC} 3 \mathrm{HO} 4-\mathrm{C} 9 \mathrm{H} 704) \rightarrow \mathrm{B}(\mathrm{FULL}(\mathrm{C} 60) \mathrm{fC} 3 \mathrm{O} 4-\mathrm{C} 18 \mathrm{H} 14 \mathrm{O} 8)+\mathrm{H}_{2}
\end{aligned}
$$

All these systems were previously optimized using the Becke's three-parameter exchange functional and the Lee, Yang and Parr functional (B3LYP) [17,18] with the 6-31G base implemented in Gaussian code 09W [19]. This level of theory was chosen because in previous work on nanomaterials, its results are very similar to experimental results [20]. The systems were visualized with GaussView 5 [21]. From the results, the binding energies $\left(\mathrm{E}_{\mathrm{b}}\right)$ between the ASA molecule and the nanovectors have been calculated from equations (3) and (4) as follows [22-25]:

$\mathrm{E}_{\mathrm{b}}^{\mathrm{A}}=\mathrm{E}(\mathrm{FULL}(\mathrm{C} 60) \mathrm{fC} 3 \mathrm{HO} 4-\mathrm{C} 9 \mathrm{H} 704)-\mathrm{E}(\mathrm{FULL}(\mathrm{C} 60) \mathrm{fC} 3 \mathrm{HO} 4)-\mathrm{E}(\mathrm{C} 9 \mathrm{H} 7 \mathrm{O} 4)+\mathrm{E}(\mathrm{BSSE})$

$\mathrm{E}_{\mathrm{b}}^{\mathrm{B}}=\mathrm{E}(\mathrm{FULL}(\mathrm{C} 60) \mathrm{fC} 304-\mathrm{C} 18 \mathrm{H} 1408)-\mathrm{E}(\mathrm{FULL}(\mathrm{C} 60) \mathrm{fC} 304)-2 \mathrm{E}(\mathrm{C} 9 \mathrm{H} 704)+\mathrm{E}(\mathrm{BSSE})$

where $\mathrm{E}(\mathrm{FULL}(\mathrm{C} 60) \mathrm{fC} 3 \mathrm{HO} 4-\mathrm{C} 9 \mathrm{H} 7 \mathrm{O} 4)$ and $\mathrm{E}(\mathrm{FULL}(\mathrm{C} 60) \mathrm{fC} 3 \mathrm{O} 4-\mathrm{C} 18 \mathrm{H} 14 \mathrm{O} 8)$ are respectively the electronic energies of fullerene ylide functionalized to one radical of the aspirin molecule and fullerene ylide functionalized to two radicals of the aspirin molecules. $\mathrm{E}(\mathrm{FULL}(\mathrm{C} 60) \mathrm{fC} 3 \mathrm{HO} 4)$ and $\mathrm{E}(\mathrm{FULL}(\mathrm{C} 60) \mathrm{fC} 3 \mathrm{O} 4)$ are the electronic energies of the radicals of fullerene ylide. $\mathrm{E}(\mathrm{C} 9 \mathrm{H} 7 \mathrm{O} 4)$ is the electronic energy of a radical of the aspirin molecule. Calculations of the binding energy have been corrected by the basis set superposition error $\mathrm{E}(\mathrm{BSSE})$, calculated from the counterpoise method of Boys and Bernardi [26]. Due to the insufficiency of gas phase results to describe the influence of solvents, the solvation effect was studied using water $(\varepsilon=78.4)$ with the formalism of the Integral Equation Polarized Continuum Model (IEFPCM) [27]. The SMD continuum model of Marenich et al [28] was used to correct the total energies in water, based on the corrections of the polarized continuum model $\left(\mathrm{E}_{\mathrm{corr}}^{\mathrm{PCM}}\right)$; from which we determined Gibbs free energies of solvation $\left(\Delta \mathrm{G}_{\mathrm{sol}}\right)$.

Non-linear optics (NLO) parameters, such as mean polarisability, first-order static hyperpolarizability and dipole moment, were calculated using equations found in the literature $[29,30]$. The molecular orbital data used to plot the density of states (DOS) were obtained using GaussSum 2.2 software [31]. Electronegativity $(\chi)$ and hardness $(\eta)$ are respectively related to chemical potential $(\mu)$ and softness $(S)$. The electrophilicity index $(\omega)$ is derived from the values of $\mu$ and $\eta$. All these global descriptors of molecular reactivity were calculated from ionization potential (IP) and electronic affinity (EA) using the equations reported in the literature [32]. The fractional number of electrons transferred from system $\mathrm{X}$ (aspirin molecule) to system $\mathrm{Y}$ (one of the two nanostructures $\mathrm{A}$ or $\mathrm{B}$ ) was calculated by the parameter $\Delta \mathrm{N}$ [33] using equation (5):

$$
\Delta N=\left(\mu_{Y}-\mu_{X}\right) / 2\left(\eta_{X}+\eta_{Y}\right)
$$

where $\mu_{X}$ and $\mu_{Y}$ are the chemical potentials of $\mathrm{X}$ and $\mathrm{Y}$ systems, while $\eta_{X}$ and $\eta_{Y}$ are hardnesses of $\mathrm{X}$ and $\mathrm{Y}$ systems. The parameter $\Delta \mathrm{N}$ shows the overall interaction between $\mathrm{X}$ and $\mathrm{Y}$ molecular systems. $\mathrm{X}$ acts as an electron acceptor if $\Delta \mathrm{N}$ is positive and charges flow from $\mathrm{Y}$ to $\mathrm{X}$; inversely, $\mathrm{X}$ acts as an electron donor if $\Delta \mathrm{N}$ is negative and charges flow from $\mathrm{X}$ to $\mathrm{Y}$. 


\section{Results and discussions}

3.1. Optimized molecular structures, binding energies, vibrational analyses and Gibbs free energy of the studied molecular structures

The optimized geometries of the aspirin molecule, fullerene ylide, nanostructures A and B are shown graphically in Figure 1. Some bond lengths and angles of the aspirin radicals of the studied molecular structures are shown in Table 1 below.

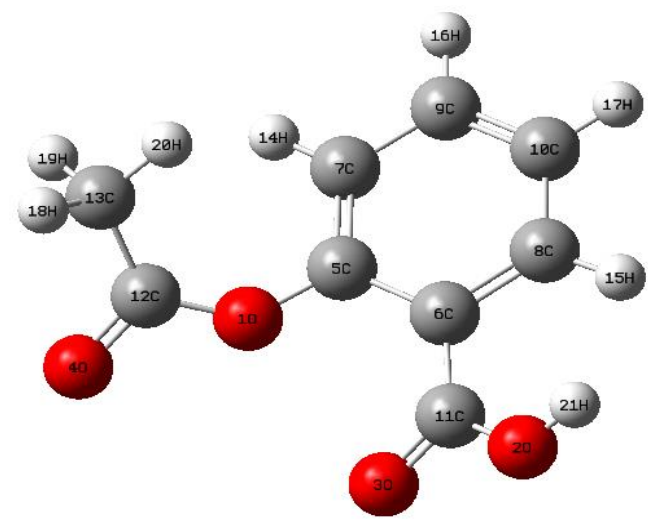

(a) Acetylsalicylic acid

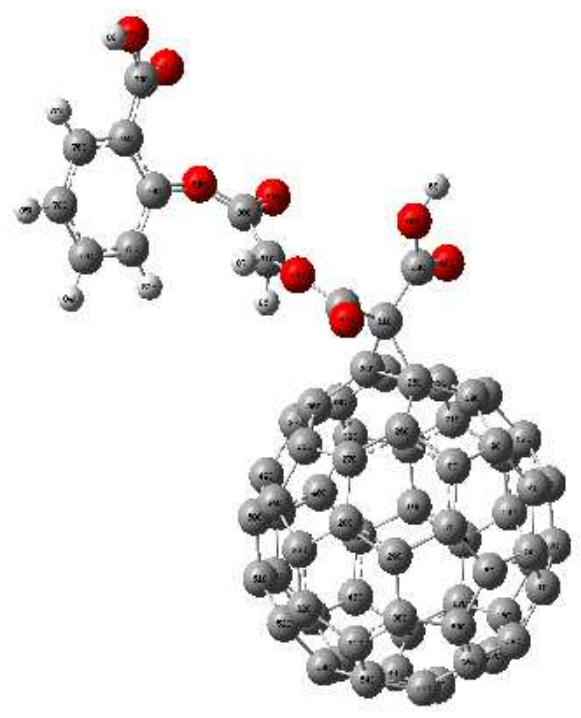

(c) Nanostructure A

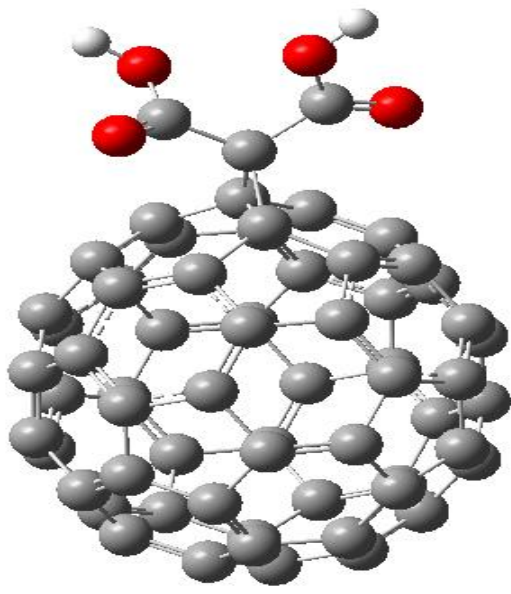

(b) Fullerene ylide

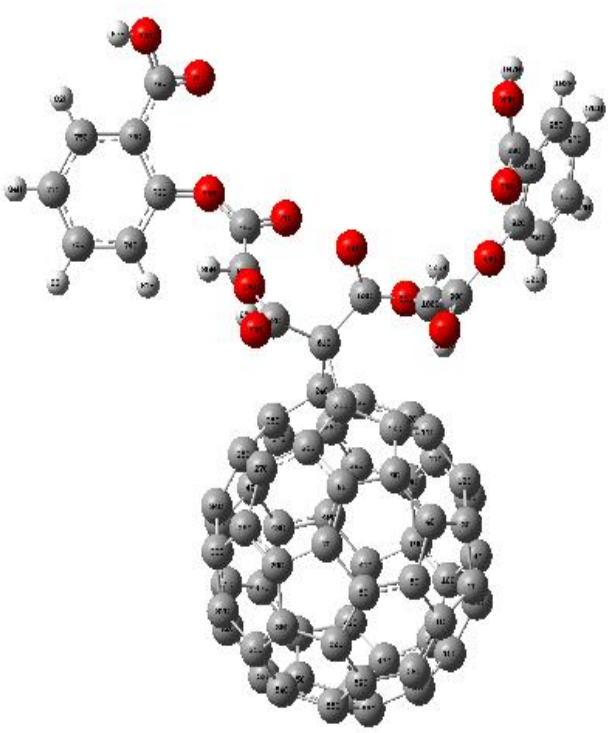

(d) Nanostructure B

Figure 1: Optimized geometries of (a) Acetylsalicylic acid (ASA), (oxygen atoms are colored red, carbon grey, and hydrogen white); (b) FULL(C60)fC3H2O4 (Fullerene ylide); (c) FULL(C60)fC3HO4-C9H704 (nanostructure A); and (d) FULL(C60)fC3O4-C18H1408 (nanostructure B) in gas phase.

The results of bond lengths and angles of the simulated aspirin radical are slightly different from the experimental values given by the work of Yunfeng Ye et al [34]. These differences are due to the fact that the simulations are carried out on isolated molecules, whereas the experimental work is carried out on package of molecules in solid phase. During the first 
functionalization on nanostructure $\mathrm{A}$, the maximum change between the bond lengths of the isolated aspirin molecule and the aspirin radical on nanostructure $A$ is about $0.036 \AA$ and corresponds to the $\mathrm{O} 1-\mathrm{C} 12$ bond. For the bond angles, the maximum change between the isolated aspirin molecule and the aspirin radical on the nanostructure $\mathrm{A}$ is about $4.737^{\circ}$ and is found on the C6-C5-O1 bond angle. These differences are due to the functionalization of a foreign system (fullerene ylide) and the system is trying to stabilize itself. During the second functionalization on nanostructure $\mathrm{B}$, the differences between the lengths and bond angles of the first aspirin radical on nanostructure $\mathrm{A}$ and the second aspirin radical on nanostructure $\mathrm{B}$ are reduced, due to the equivalent sharing charges provided by the nanovector. Fullerene (C60) undergoes a slight distortion of the lengths of the $\mathrm{C}-\mathrm{C}$ bonds at the site of covalent functionalization with the carbonyl ylide functional group. This distortion is due to the pole of functionalization and is coherent with the results presented by Veloso et al [35]. The change in hybridization from sp2 to sp3 at the site of functionalization leads to a change in the length of the C-C bond [6-6] (hexagonal bond) of the fullerene from $1.38 \AA$ to $1.58 \AA$ for both nanostructures.

Table 1: Molecular geometrical parameters in gas phase of the studied molecule of acetylsalicylic acid and radicals of acetylsalicylic acid functionalized on nanostructures.

\begin{tabular}{cccccc}
\hline & $\begin{array}{c}\text { ASA } \\
\text { (B3LYP 6-31G) }\end{array}$ & $\begin{array}{c}\text { Nanostructure A } \\
(B 3 L Y P \text { 6-31G) }\end{array}$ & $\begin{array}{c}\text { Nanostructure B } \\
(B 3 L Y P \text { 6-31G })\end{array}$ & $\begin{array}{c}\text { ASA } \\
\text { Experimental } \\
{[34]}\end{array}$ \\
\hline $\begin{array}{c}\text { Bond lengths (Å) } \\
\text { C6-C11 }\end{array}$ & 1.490 & 1.494 & 1.491 & 1.493 & 1.498 \\
C11-O3 & 1.229 & 1.231 & 1.241 & 1.244 & 1.235 \\
C11-O2 & 1.390 & 1.379 & 1.385 & 1.355 & 1.287 \\
C5-O1 & 1.396 & 1.414 & 1.414 & 1.411 & 1.402 \\
O1-C12 & 1.418 & 1.382 & 1.385 & 1.401 & 1.364 \\
C12-O4 & 1.218 & 1.224 & 1.224 & 1.217 & 1.183 \\
Bond angles () & & & & & \\
C5-C6-C11 & 121.952 & 122.409 & 123.537 & 121.968 & 124.6 \\
C5-C6-C8 & 117.658 & 118.004 & 118.119 & 117.382 & 117.7 \\
C11-C6-C8 & 120.350 & 119.585 & 118.342 & 120.614 & 117.7 \\
C6-C5-O1 & 124.381 & 119.644 & 119.987 & 124.418 & 121.6 \\
C7-C5-O1 & 114.954 & 118.731 & 118.650 & 114.312 & 117.3 \\
C6-C11-O3 & 125.275 & 125.139 & 124.788 & 122.216 & 119.1 \\
C6-C11-O2 & 116.645 & 115.096 & 116.008 & 118.569 & 118.1 \\
O3-C11-O2 & 118.076 & 119.735 & 119.025 & 119.164 & 122.9 \\
C5-01-C12 & 127.851 & 126.494 & 124.925 & 125.452 & 115.7 \\
O1-C12-O4 & 116.921 & 119.315 & 119.643 & 119.938 & 122.9 \\
O1-C12-C13 & 117.838 & 121.098 & 120.063 & 114.858 & 110.7 \\
O4-C12-C13 & 125.199 & 119.541 & 120.248 & 124.057 & 126.4 \\
\hline
\end{tabular}

The stability of nanostructures A and B is determined by calculating the binding energies between the radical of the aspirin molecule, the radicals of the fullerene ylide and the two nanovectors as presented in equations (3) and (4). Table 2 shows the binding energies (Eb) of nanostructures A and B in the gas phase and in aqueous solution. As shown in Table 2, all values of the binding energies are negative, which means that the functionalizations of the aspirin radicals on the nanostructures are energetically favorable. The binding energies of 
nanostructures A and B in the gas phase are -63.346 and $-111.587 \mathrm{kcal} / \mathrm{mol}$, respectively, while in aqueous solution these values are -50.236 and $-98.628 \mathrm{kcal} / \mathrm{mol}$, respectively. The order of the BSSE corrections on the binding energies of nanostructures A and B is respectively about 8.249 and $16.776 \mathrm{kcal} / \mathrm{mol}$ and this is very significant during the formation process of our nanostructures. From these results it can be concluded that the formation process of nanostructure B is energetically more favorable than that of nanostructure A. The increase in the number of functionalized aspirin molecules on the nanovector increases the energy stability of the formed nanostructures.

Table 2: Binding energies $\left(\mathrm{E}_{\mathrm{b}}\right)$ of covalent attachment of radical of acetylsalicylic acid to the nanovector in gas phase and aqueous solution.

\begin{tabular}{lcccc}
\hline & \multicolumn{2}{c}{ Nanostructure A } & \multicolumn{2}{c}{ Nanostructure B } \\
\hline & Gas phase & $\begin{array}{c}\text { Aqueous } \\
\text { solution }\end{array}$ & Gas phase & $\begin{array}{c}\text { Aqueous } \\
\text { solution }\end{array}$ \\
\hline $\begin{array}{l}\text { Binding energy, } \\
\text { Eb (in kcal/mol) }\end{array}$ & -63.346 & -50.236 & -111.587 & -98.628 \\
\hline
\end{tabular}

In order to confirm the stability of the nanostructures, calculations of vibrational frequencies were performed. Figure 2 shows the IR and Raman vibrational spectra of the aspirin molecules and the nanostructures A and B. From the vibrational spectra no imaginary frequency appears, which proves that the nanostructures are stable and that the minima found are local minima. Some vibrational modes of these nanostructures have been studied and compared to experimental values listed in the literature, as shown in Table 3. The $\mathrm{O}-\mathrm{H}$ stretching vibration is experimentally observed at $3480 \mathrm{~cm}^{-1}$ in the literature [36]. In the vibrational spectra of the aspirin molecule and of the nanostructures $A$ and $B$, the peaks at $3654 \mathrm{~cm}^{-1}, 3605 \mathrm{~cm}^{-1}$ and 3454 $\mathrm{cm}^{-1}$ correspond respectively to those of the $\mathrm{O}-\mathrm{H}$ vibration. The $\mathrm{C}-\mathrm{H}$ stretching vibration is experimentally observed at $3090 \mathrm{~cm}^{-1}$ in the literature [37]. This $\mathrm{C}-\mathrm{H}$ stretching vibration is observed at $3154 \mathrm{~cm}^{-1}, 3112 \mathrm{~cm}^{-1}$ and $3110 \mathrm{~cm}^{-1}$ respectively on the aspirin molecule and the nanostructures $\mathrm{A}$ and $\mathrm{B}$. It is reported in the literature that the experimental value of the $\mathrm{C}=\mathrm{O}$ stretching vibration is in the range [1658.4-1748.4] $\mathrm{cm}^{-1}[38]$. The $\mathrm{C}=\mathrm{O}$ stretching vibrations are theoretically observed in the regions [1753.3-1793.8] $\mathrm{cm}^{-1},[1749.1-1760.2] \mathrm{cm}^{-1}$ and [1664.1-1730.4] $\mathrm{cm}^{-1}$ in the aspirin molecule and nanostructures $\mathrm{A}$ and $\mathrm{B}$, respectively. The $\mathrm{C}=\mathrm{C}$ stretching vibrations are experimentally observed at $1606 \mathrm{~cm}^{-1}$ in the literature [39]. This $\mathrm{C}=\mathrm{C}$ stretching vibration is theoretically observed at $1658 \mathrm{~cm}^{-1}, 1635 \mathrm{~cm}^{-1}$ and $1631 \mathrm{~cm}^{-1}$ respectively for the aspirin molecule and nanostructures A and B. All these values are in agreement with the experimental values if one takes into account the scale factor of 0.9613 appropriate for vibrational analysis with the B3LYP/6-31G(d) method [40].

The degree of solubility of a substance can be predicted by the Gibbs free energy of solvation $\left(\Delta \mathrm{G}_{\mathrm{sol}}\right)$. The degree of solubility increases with decreasing $\Delta \mathrm{G}_{\mathrm{sol}}$ and the molecular system is more soluble if $\Delta \mathrm{G}_{\mathrm{sol}}$ is more negative [41]. The calculated values of the total energies $\mathbf{E}_{\mathbf{c o r r}}^{\mathbf{P C M}}$ after correction are -648.5067, -3349.1619 and -3996.4493 Hartree for the aspirin molecule, and nanostructures $\mathrm{A}$ and $\mathrm{B}$, respectively. The $\Delta \mathrm{G}_{\text {sol }}$ values are $-23.65,-40.14$ and $-56.45 \mathrm{kcal} / \mathrm{mol}$ for the aspirin molecule and nanostructures $\mathrm{A}$ and $\mathrm{B}$, respectively. According to the work of Zafar et al [42], good therapeutic molecules should have a value of $\Delta \mathrm{G}_{\text {sol }}$ below $-12 \mathrm{kcal} / \mathrm{mol}$. According to Table 4, all these systems are good candidates for therapeutic effect. Furthermore, by passing from the aspirin molecule to the nanostructure A, 
$\Delta \mathrm{G}_{\text {sol }}$ decreases by about $-16.49 \mathrm{kcal} / \mathrm{mol}$; this reflects the fact that functionalization increases the solubility of a molecule. Also, when moving from nanostructure $\mathrm{A}$ to nanostructure $\mathrm{B}, \Delta \mathrm{G}_{\text {sol }}$ decreases by about $-16.31 \mathrm{kcal} / \mathrm{mol}$; this reflects the fact that multifunctionalization makes molecules more soluble.
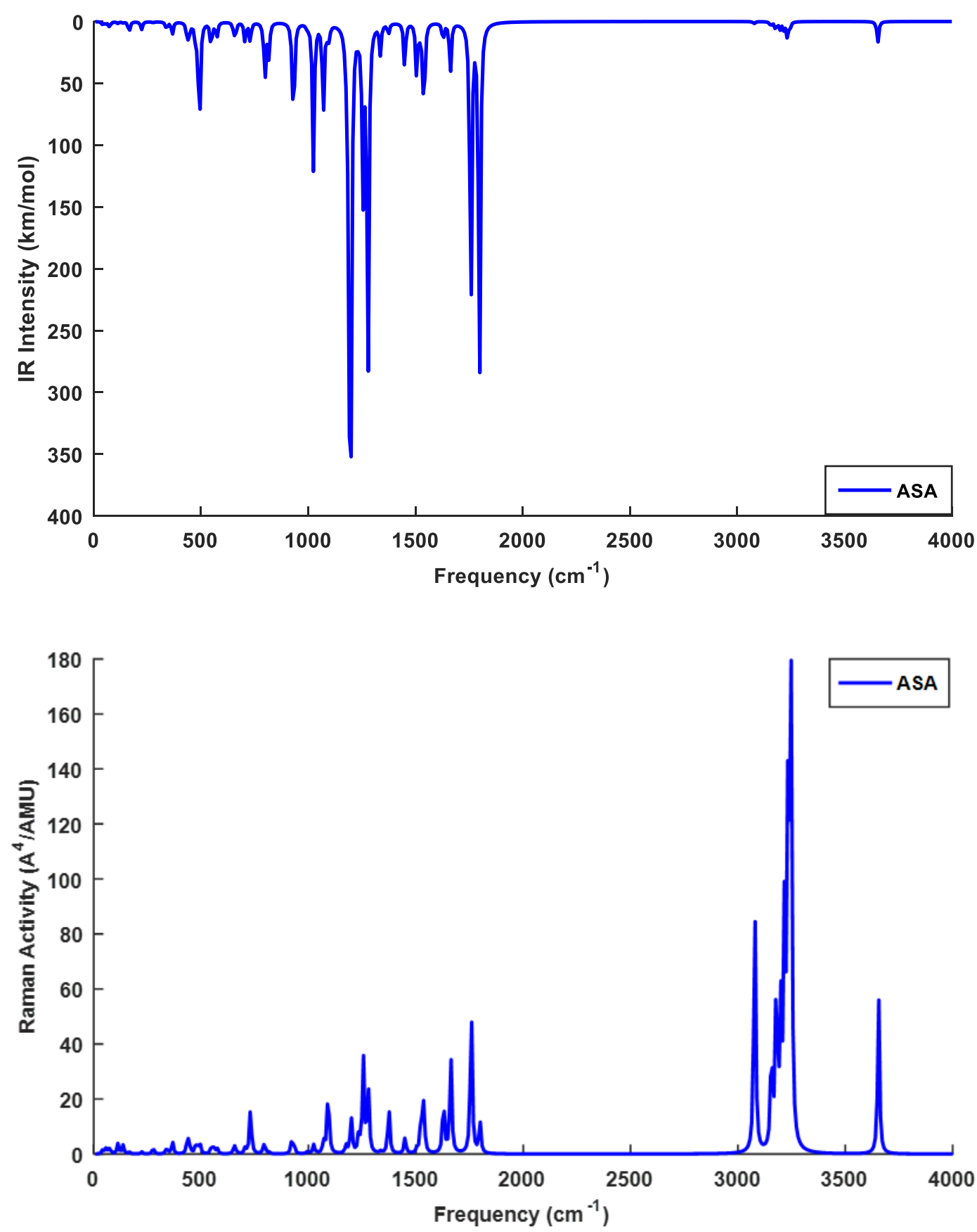

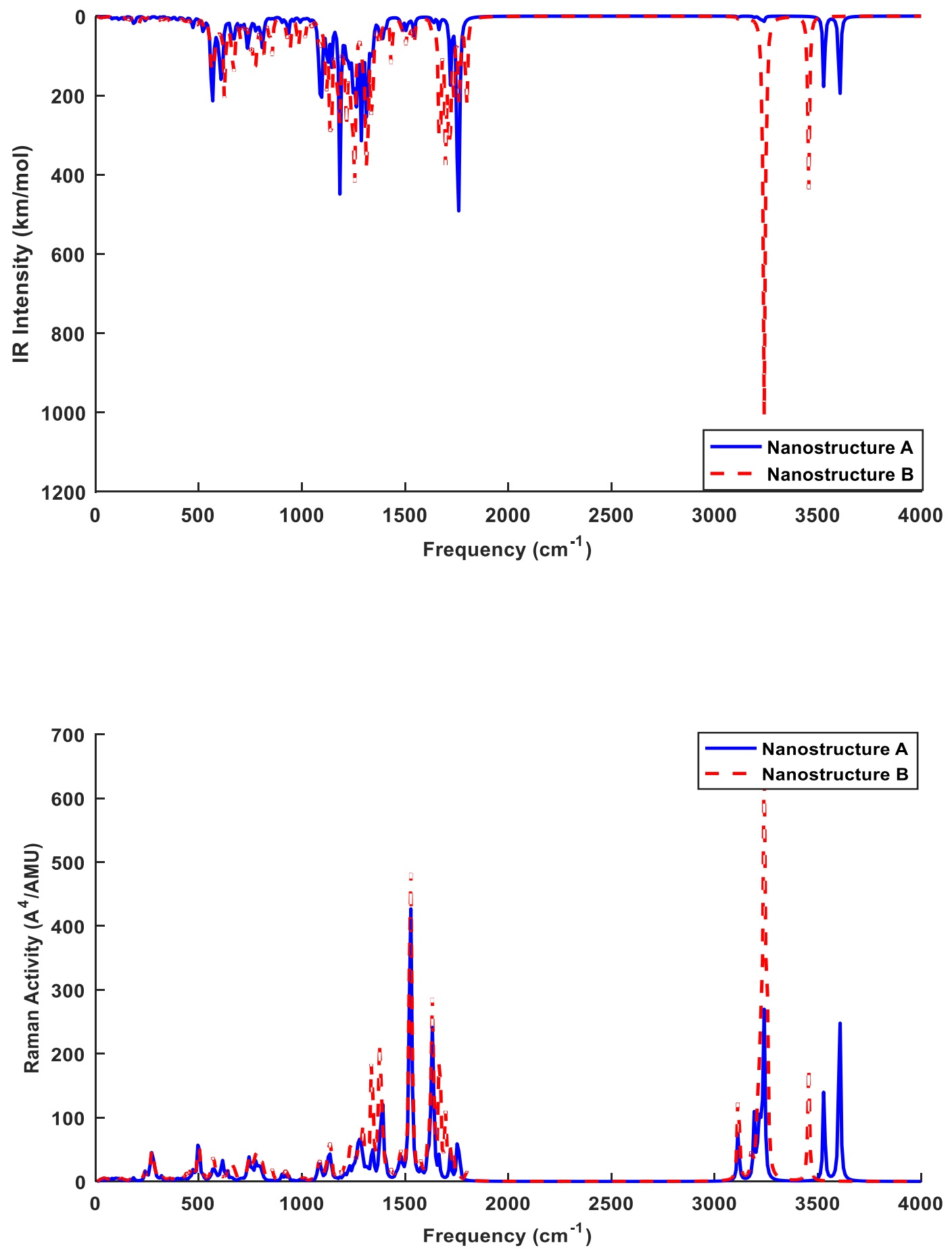

Figure 2: Vibrational IR and Raman spectra of the molecules of acetylsalicylic acid, nanostructures $\mathrm{A}$ and $\mathrm{B}$. 
Table 3: Vibrational frequencies and assignments of some modes of the studied molecular structures.

\begin{tabular}{ccccc}
\hline \multicolumn{2}{c}{ Computed vibrational frequencies $\left(\mathrm{cm}^{-1}\right)$} & $\begin{array}{c}\text { Experimentals } \\
\text { vibrational } \\
\text { frequencies }\left(\mathrm{cm}^{-1}\right)\end{array}$ & Assignments \\
\hline ASA & Nanostructure A & Nanostructure B & & \\
\hline 3654 & 3605 & 3454 & $3480^{\mathrm{a}}$ & O-H stretching \\
3154 & 3112 & 3110 & $3090^{\mathrm{b}}$ & $\mathrm{C}-\mathrm{H}$ stretching \\
$1753.3-1793.8$ & $1749.1-1760.2$ & $1664.1-1730.4$ & $1658.4-1748.4^{\mathrm{c}}$ & $\mathrm{C}=\mathrm{O}$ stretching \\
1658 & 1635 & 1631 & $1606^{\mathrm{d}}$ & $\mathrm{C}=\mathrm{C}$ stretching \\
\hline
\end{tabular}

${ }^{\text {aFrom Ref. [36] }}$

${ }^{\text {bFrom Ref. [37] }}$

'From Ref. [38]

${ }^{\text {d}}$ From Ref. [39]

Table 4: Gibbs free energy of solvation of the studied molecular structures.

\begin{tabular}{lccc}
\hline & ASA & Nanostructure A & Nanostructure B \\
\hline Total energy after & -648.5067 & -3349.1619 & -3996.4493 \\
PCM correction, & & & \\
$\mathbf{E}_{\text {corr }}^{\text {PCM (in Hartree) }}$ & & & \\
\hline $\begin{array}{c}\text { Gibbs free energy } \\
\text { of solvation, }\end{array}$ & -23.65 & -40.14 & -56.45 \\
$\Delta \mathrm{G}_{\text {sol }}$ (in kcal/mol) & & & \\
\hline
\end{tabular}

\subsection{Non-linear optical and electronic properties of molecular structures}

According to Table 5, all non-linear electronic and optical properties of molecular systems increase more in aqueous solution than in the gas phase. As the data in Table 5 clearly show, when aspirin is adsorbed on the surface of the fullerene ylide, the dipole moment increases from 11.855 to $12.500 \mathrm{D}$ for nanostructures $\mathrm{A}$ and from 11.855 to $20.536 \mathrm{D}$ for nanostructures $\mathrm{B}$ in aqueous solution. Therefore, the solubility and bioavailability of aspirin increases significantly when adsorbed on the surface of fullerene ylide [25]. According to Table 5, the theoretical values of the first-order static hyperpolarizability of nanostructures $A$ and B are $1881.4889 \times 10^{-}$ ${ }^{53}$ and $1899.6860 \times 10^{-53} \mathrm{C}^{3} \mathrm{~m}^{3} \mathrm{~J}^{-2}$ in gas phase, $4980.0293 \times 10^{-53}$ and $6435.6970 \times 10^{-53} \mathrm{C}^{3} \mathrm{~m}^{3} \mathrm{~J}^{-2}$ in aqueous solution, respectively. The first-order static hyperpolarizabilities of nanostructures A and B are respectively of the order of 2.267 and 2.289 times greater than those of the aspirin molecule in the gas phase and 3.404 and 4.399 times greater in aqueous solution.

Urea is an organic molecule generally considered as a reference for the comparison of good nonlinear optical properties [43]. The first-order static hyperpolarizability of nanostructures A and $\mathrm{B}$ in aqueous solution is respectively 35.991 and 46.512 times greater than that of urea $\left(\beta_{0}=138.365 \times 10^{-53} \mathrm{C}^{3} \mathrm{~m}^{3} \mathrm{~J}^{-2}\right)$. This shows that these nanostructures are good candidates as materials for applications in nonlinear optics. In addition, multifunctionalization significantly improves the nonlinear optical properties of nanomaterials. 
Table 5: Non-linear optical and electronic properties (dipole moment $\mu_{0}\left(\times 10^{-30} \mathrm{Cm}\right)$, mean polarizability $\alpha_{0}\left(\mathrm{x} 10^{-41} \mathrm{C}^{2} \mathrm{~m}^{2} \mathrm{~J}^{-1}\right)$, static first-order hyperpolarizability $\beta_{0}\left(\mathrm{x} 10^{-53} \mathrm{C}^{3} \mathrm{~m}^{3} \mathrm{~J}^{-2}\right)$,

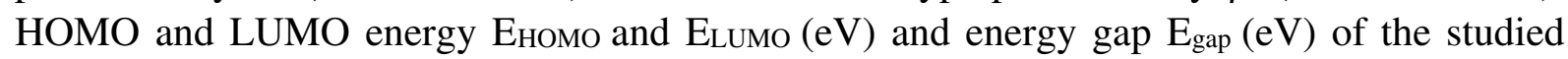
systems in gas phase and aqueous solution.

\begin{tabular}{ccccccc}
\hline & \multicolumn{2}{c}{ ASA } & \multicolumn{2}{c}{ Nanostructure A } & \multicolumn{2}{c}{ Nanostructure B } \\
\hline Properties & Gas phase & $\begin{array}{c}\text { Aqueous } \\
\text { solution }\end{array}$ & Gas phase & $\begin{array}{c}\text { Aqueous } \\
\text { solution }\end{array}$ & Gas phase & $\begin{array}{c}\text { Aqueous } \\
\text { solution }\end{array}$ \\
\hline $\boldsymbol{\mu}_{\mathbf{0}}$ & 8.4705 & 11.8552 & 8.8634 & 12.5004 & 9.3671 & 20.5360 \\
$\boldsymbol{\alpha}_{\mathbf{0}}$ & 164.6637 & 209.7628 & 1014.4105 & 1640.3100 & 1199.7148 & 1881.9907 \\
$\boldsymbol{\beta}_{\mathbf{0}}$ & 829.7745 & 1462.7841 & 1881.4889 & 4980.0293 & 1899.6860 & 6435.6970 \\
E $_{\text {HOMO }}$ & -7.2640 & -7.2981 & -6.2618 & -6.0199 & -6.1114 & -6.0134 \\
ELUMO $_{\text {LU }}$ & -2.0996 & -1.9214 & -3.5619 & -3.3097 & -3.4188 & -3.3078 \\
Egap $_{\text {gap }}$ & 5.1643 & 5.3707 & 2.6999 & 2.7101 & 2.6925 & 2.7056 \\
\hline
\end{tabular}

The total densities of states (DOS), HOMO and LUMO orbitals of the simulated gas phase molecular structures are shown in Figures 3 and 4. The molecular orbitals of nanostructures A and B are mainly distributed on fullerenes (see Figure 4). This region is therefore more active for electrophilic and nucleophilic sites. Similarly, functionalization improves the electronic gap (Egap) of the aspirin molecule from $5.1643 \mathrm{eV}$ to $2.6999 \mathrm{eV}$ for nanostructure A and $2.6925 \mathrm{eV}$ for nanostructure B in the gas phase (see Table 5). In aqueous solution, the band gap (Egap) increases from $5.3707 \mathrm{eV}$ for the aspirin molecule to $2.7101 \mathrm{eV}$ for nanostructure A and $2.7056 \mathrm{eV}$ for nanostructure B. Consequently, the solvation effect slightly increases the electronic gaps of the studied molecules. The passage of the functionalization of one aspirin molecule (nanostructure A) and two aspirin molecules (nanostructure B) slightly varies the electronic gap. Multifunctionalization makes the electronic properties of the modeled nanostructures vary very slightly. Moreover, the calculated band gap values of nanostructures A and B are slightly better than those of the pristine fullerene (2.77 $\mathrm{eV}$ ), as published by Shukla and Leszcynski [44].
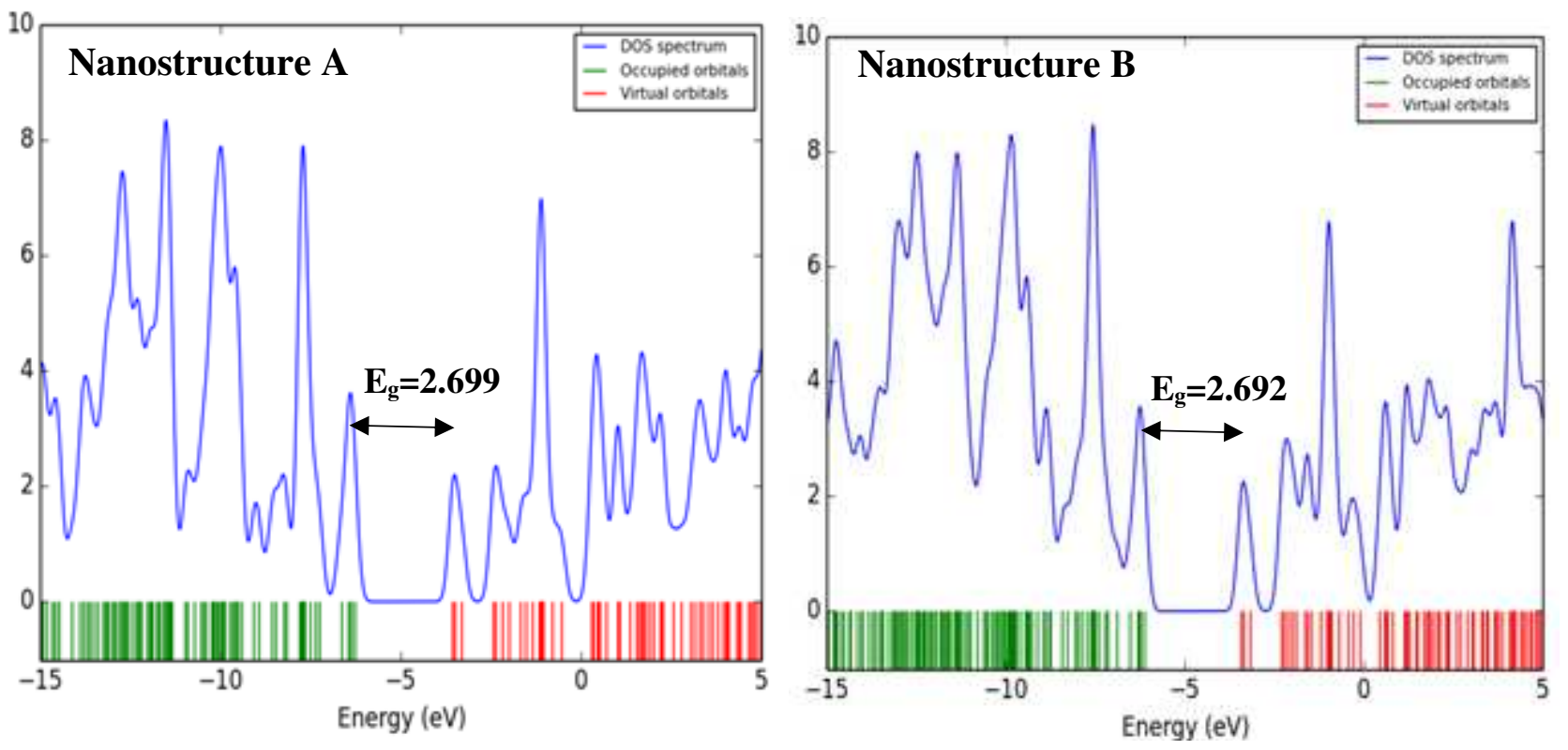

Figure 3: Densities of states of the studied nanostructures in gas phase. 

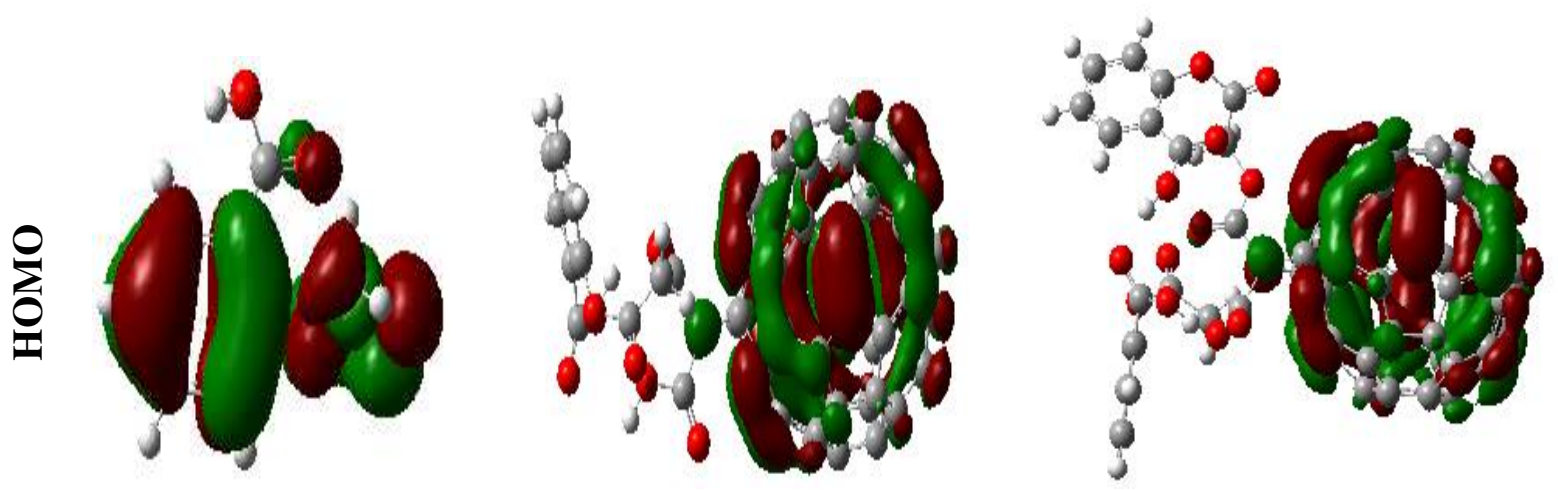

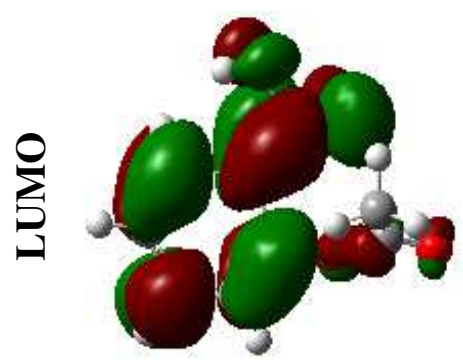

ASA

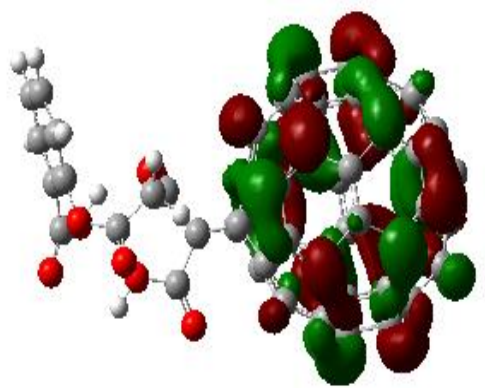

Nanostructure A

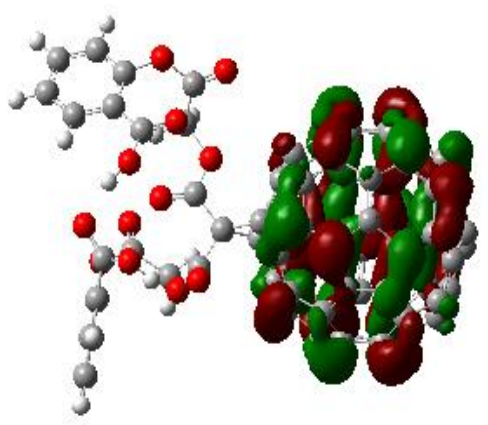

Nanostructure B

Figure 4: HOMO and LUMO molecular orbital diagrams of the studied molecular structures.

\subsection{Quantum molecular descriptors of the studied molecular structures}

According to Table 6 , all the values of the global reactivity descriptors EA, IP, $\chi, \mu, \eta$ and $\omega$ of the aspirin molecule are in agreement with the results published in the literature by Kayadibi et al. [45] using the same method. Nanostructures A and B have high EA and IP values, which means that they are good electron acceptors and donors. A soft molecule is more reactive than a hard molecule because the hard molecule has a large energy difference [46]. According to Table 6, nanostructures A and B are softer than the aspirin molecule because their chemical hardness $(n)$ is lower and their softness $(S)$ is greater, and therefore they are more reactive. The electrophilic index $(\omega)$ indicates the stabilization energy of a molecular system at the time of reception of electrons from the environment, and a high or low value of $\omega$ means a good electrophilic or nucleophilic compound, respectively [47]. Nanostructures A and B have a higher electrophilicity index $(\omega)$ than the aspirin molecule and are therefore more electrophilic. In nanostructures $\mathrm{A}$ and $\mathrm{B}$, the values of $\Delta \mathrm{N}$ are negative, so the radicals of the aspirin molecule act as electron donors to the nanovector, and the charges are transferred from the radical of the aspirin molecule to the nanovector. When switching from nanostructure A to nanostructure B through multifunctionalization, the amount of charges transferred decreases because instead of one radical in the aspirin molecule, there are now two radicals that transmit the charges. 
Table 6: Quantum molecular descriptors of the studied molecular structures in gas phase and aqueous solution.

\begin{tabular}{cccccccc}
\hline & \multicolumn{2}{c}{ Nanostructure A } & \multicolumn{2}{c}{ Nanostructure B } & \multicolumn{2}{c}{ ASA } & $\begin{array}{c}\text { ASA } \\
\text { (Theoretical) } \\
{[45]}\end{array}$ \\
\hline $\begin{array}{c}\text { Quantum } \\
\text { molecular } \\
\text { Descriptors }\end{array}$ & $\begin{array}{c}\text { Gas } \\
\text { phase }\end{array}$ & $\begin{array}{c}\text { Aqueous } \\
\text { solution }\end{array}$ & $\begin{array}{c}\text { Gas } \\
\text { phase }\end{array}$ & $\begin{array}{c}\text { Aqueous } \\
\text { solution }\end{array}$ & $\begin{array}{c}\text { Gas } \\
\text { phase }\end{array}$ & $\begin{array}{c}\text { Aqueous } \\
\text { solution }\end{array}$ & Gas phase \\
\hline EA/eV & 3.5619 & 3.3097 & 3.4188 & 3.3078 & 2.0996 & 1.9214 & 1.380 \\
$\mathrm{IP} / \mathrm{eV}$ & 6.2618 & 6.0199 & 6.1114 & 6.0134 & 7.2640 & 7.2981 & 7.052 \\
$\chi / \mathrm{eV}$ & 4.9118 & 4.6648 & 4.7651 & 4.6606 & 4.6818 & 4.6097 & 4.216 \\
$\mu / \mathrm{eV}$ & -4.9118 & -4.6648 & -4.7651 & -4.6606 & -4.6818 & -4.6097 & - \\
$\mathrm{n} / \mathrm{eV}$ & 1.3499 & 1.3551 & 1.3463 & 1.3528 & 2.5822 & 2.6883 & 2.836 \\
$\mathrm{~S} / \mathrm{eV}-1$ & 0.7407 & 0.7379 & 0.7427 & 0.7392 & 0.3872 & 0.3719 & 0.353 \\
$\omega / \mathrm{eV}$ & 8.9361 & 8.0290 & 8.4328 & 8.0282 & 4.2443 & 3.9521 & 3.13 \\
$\Delta \mathrm{N} / \mathrm{e}$ & -0.0292 & -0.0068 & -0.0106 & -0.0062 & - & - & - \\
\hline
\end{tabular}

Figure 5 shows the distribution over the surface of the total electron density represented with the electrostatic potential of nanostructures A and B. The potential increases in the following order: red < orange < yellow < green < blue. Atoms located in the red region are negative potential sites and participate in electrophilic reactions, while atoms located in the blue regions are positive and participate in nucleophilic reactions. Oxygen atoms are sites with a more negative potential and participate in electrophilic reactions. Carbon and hydrogen atoms are positive potential sites and participate in nucleophilic reactions. Thus, the functionalization reaction was carried out on two suitable sites namely: oxygen (electrophilic for the fullerene ylide) with the carbon of the methyl group (nucleophilic for the aspirin radical).

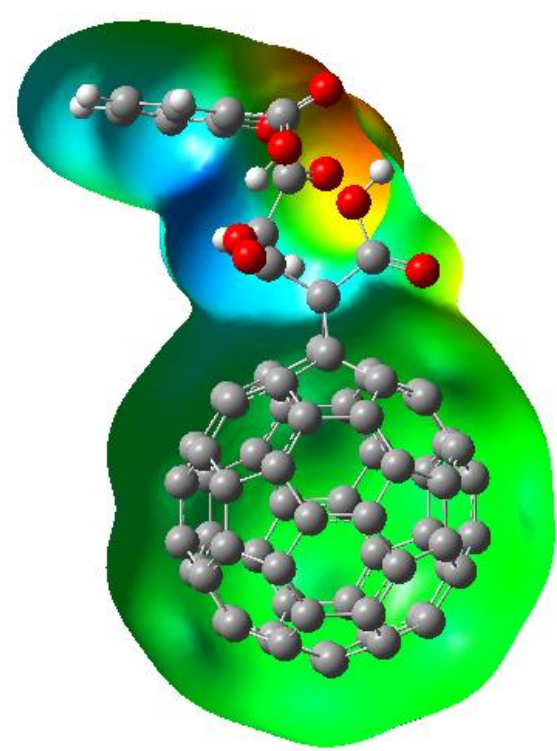

Nanostructure A

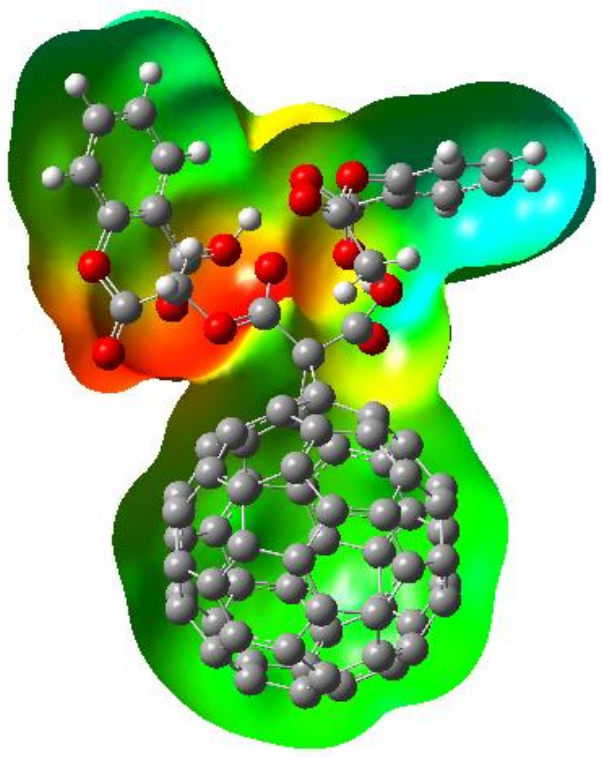

Nanostructure B

Figure 5: Total electron densities mapped with electrostatic potential of modeled nanostructures 


\section{Conclusion}

We have performed DFT calculations on nanostructures A and B obtained respectively by the functionalization on fullerene ylide of an acetylsalicylic acid (ASA) or aspirin molecule and two aspirin molecules. The results show us that the process of formation of these nanostructures is energetically favorable. The increase in the number of aspirin molecules functionalized on fullerene ylide increases the energy stability of the formed nanostructures. The analysis of the vibrational spectra of these nanostructures shows the inexistence of imaginary frequencies. Thus, the formed systems are stable and present some vibrational modes in accordance with the experimental data. The process of solvation in water of these systems is spontaneous. Moreover, the degree of solubility of these nanostructures increases with the number of functionalized molecules. Multifunctionalization considerably improves the nonlinear optical properties and allows to obtain nanostructures that can be good candidates as materials for nonlinear optical applications. By functionalizing an isolated aspirin molecule for nanostructure $\mathrm{A}$, the electronic gap is considerably reduced, but by passing to multifunctionalization, the electronic properties of nanostructure B vary very slightly compared to nanostructure A. Nanostructures A and B are soft, more electrophilic and more reactive than the aspirin molecule. During the functionalization of nanostructures $\mathrm{A}$ and $\mathrm{B}$, charges are transferred from the radical of the aspirin molecule to the nanovector. However, the amount of charges transferred decreases when multifunctionalization is performed because instead of one radical in the aspirin molecule, there are now two radicals that transmit the charges. The sites of the oxygen atoms are electrophilic, while the sites of the carbon and hydrogen atoms are nucleophilic.

\section{Conflicts of interest}

The authors declare that there is no conflict of interest as concerns this article.

\section{Acknowledgements}

We are thankful to the Council of Scientific and Industrial Research (CSIR), India for financial support through Emeritus Professor scheme (grant no. 21(0582)/03/EMR-II) to Late Prof. A.N. Singh of the Physics Department, Bahamas Hindu University, India which enabled him to purchase the Gaussian Software. We are most grateful to late Emeritus Prof. A.N. Singh for donating this software to one of us Prof. Geh Wilson Ejuh and to the Materials Science Laboratory of the University of Yaoundé I for enabling us use their computing facilities.

\section{Availability of data and material N/A}

Code availability The calculations have been carried out using Gaussian 09 and GaussView Version 5 provided by Gaussian, Inc.

Author's contributions There were equal contributions of the authors to the completion of this work.

\section{References}

[1] A. Hirsch, «The era of carbon allotropes,» Nature materials, vol. 9, n 11, pp. 868-871, 2010. 
[2] S. Chiashi, Y. Murakami, Y. Miyauchi et S. Maruyama, "Cold wall CVD generation of singlewalled carbon nanotubes and in situ Raman scattering measurements of the growth stage," Chemical Physics Letters, vol. 386, n 1-3, pp. 89-94, 2004.

[3] A. C. Tripathi, S. A. Saraf et S. K. Saraf, «Carbon nanotropes: A contemporary paradigm in drug delivery.," Materials, vol. 8, n 6, pp. 3068-3100, 2015.

[4] R. Partha et J. L. Conyers, «Biomedical applications of functionalized fullerene-based nanomaterials, » International journal of nanomedicine, vol. 4, pp. 261-275, 2009.

[5] C. G. Shuttle, R. Hamilton, B. C. O’Regan, J. Nelson et J. R. Durrant, «Charge-density-based analysis of the current-voltage response of polythiophene/fullerene photovoltaic devices,» Proceedings of the National Academy of Sciences, vol. 107, n 38, pp. 16448-16452, 2010.

[6] C. Michaux, C. Charlier, F. Julémont, X. de Leval, J. M. Dogne, B. Pirotte et F. Durant, «A new potential cyclooxygenase-2 inhibitor, pyridinic analogue of nimesulide,» European journal of medicinal chemistry, vol. 40, n 12, pp. 1316-1324, 2005.

[7] J. Tenenbaum, «The epidemiology of nonsteroidal anti-inflammatory drugs, Canadian Journal of Gastroenterology, vol. 13, 1999.

[8] H. Blain, J. Y. Jouzeau, P. Netter et C. Jeandel, «Les anti-inflammatoires non stéroïdiens inhibiteurs sélectifs de la cyclooxygénase 2 . Intérêt et perspectives, " La revue de médecine interne, vol. 21, n 11, pp. 978-988, 2000.

[9] H. P. Wirth, R. Hürlimann et T. Flückiger, «Les AINS et les inhibiteurs de la COX-2: principaux effets indésirables,» Forum Médical Suisse. EMH Media, n 6, pp. 284-290, 2006.

[10] M. Gallo, A. Favila et D. Glossman-Mitnik, «DFT studies of functionalized carbon nanotubes and fullerenes as nanovectors for drug delivery of antitubercular compounds, " Chemical Physics Letters, vol. 447, n 1-3, pp. 105-109, 2007.

[11] T. W. Prow, J. E. Grice, L. L. Lin, R. Faye, M. Butler, W. Becker, E. M. Wurm, C. Yoong, T. A. Robertson, H. P. Soyer et M. S. Roberts, «Nanoparticles and microparticles for skin drug delivery, " Advanced drug delivery reviews, vol. 63, n 6, pp. 470-491, 2011.

[12] W.-B. Zhang, Y. Tu, R. Ranjan, R. M. Van Horn, S. Leng, J. Wang, M. J. Polce, C. Wesdemiotis, R. P. Quirk, G. R. Newkome et S. Z. D. Cheng, "“Clicking" fullerene with polymers: synthesis of [60] fullerene end-capped polystyrene," Macromolecules, vol. 41, n³ 3, pp. 515-517, 2008.

[13] G.-W. Wang, H.-T. Yang, P. Wu, C.-B. Miao et Y. XU, «Novel cycloaddition reaction of [60] fullerene with carbonyl ylides generated from epoxides," The Journal of organic chemistry, vol. 71, n 11, pp. 4346-4348, 2006.

[14] C. Bingel, «Cyclopropylation of fullerenes,» ChemInform, vol. 25, n² 25, pp. 1957-1959, 1994.

[15] A. A. Peyghan, M. Noel et M. B. Tabar, «A large gap opening of graphene induced by the adsorption of Co on the Al-doped site," Journal of molecular modeling, vol. 19, $\mathrm{n}^{\circ} 8, \mathrm{pp} .3007-$ 3014, 2013. 
[16] R. J. Chen, Y. Zhang, D. Wang et H. Dal, «Noncovalent sidewall functionalization of single-walled carbon nanotubes for protein immobilization, » Journal of the American Chemical Society, vol. 123, n 16, pp. 3838-3839, 2001.

[17] A. D. Becke, «Density-functional thermochemistry. I. The effect of the exchange-only gradient correction," The Journal of chemical physics, vol. 96, n³, pp. 2155-2160, 1992.

[18] C. Lee, W. Yang et R. G. Parr, «Development of the Colle-Salvetti correlation-energy formula into a functional of the electron density,» Physical review B, vol. 37, n² 2, p. 785, 1988.

[19] M. J. Frisch, G. Trucks, H. Schlegel, G. Scuseria, M. Robb, J. Cheeseman, G. Calmani, V. Barone, B. Mennucci, G. Petersson, H. Nakatsuji, M. Caricato, X. Li, H. Hratchian, A. Izmaylov, J. Bloino, G. Zheng et e. al., GAUSSIANO9, Revision A. 02, vol. 121, Wallingford CT: gaussian. Inc., 2009, pp. 150-166.

[20] S. M. R. Jalali, A. Roya et F. R. Behnam, «Procarbazine adsorption on the surface of single walled carbon nanotube: DFT studies,» Chemical Review and Letters, vol. 3, n 4, pp. 175-179, 2020.

[21] R. Dennington, T. Keith et J. Millam, GaussView. version 5, Shawnee Mission, KS: Semichem Inc., 2009.

[22] Y. Tadjouteu Assatse, G. W. Ejuh, R. A. Yossa Kamsi, F. Tchoffo et J. M. B. Ndjaka, «Theoretical studies of nanostructures modeled by the binding of uracil derivatives to functionalized $(5,5)$ carbon nanotubes,» Chemical Physics Letters, vol. 731, p. 136602, 2019.

[23] I. Zanella, S. B. Fagan, R. Mota et A. Fazzio, «Ab initio study of pristine and Si-doped capped carbon nanotubes interacting with nimesulide molecules, "Chemical physics letters, vol. 439, $n^{\circ} 4-6$, pp. 348-353, 2007.

[24] E. Babanezhad et B. Abolghasem, «The possibility of selective sensing of the straight-chain alcohols (including methanol to n-pentanol) using the C20 fullerene and C18NB nano cage,» Chemical Review and Letters, vol. 1, n² 2, pp. 82-88, 2018.

[25] M. R. J. Sarvestani et D. Zohreh, «Fullerene (C20) as a potential sensor for thermal and electrochemical detection of amitriptyline: A DFT study,» J. Chem. Lett, vol. 1, pp. 63-68, 2020.

[26] S. F. Boys et F. Bernardi, «The calculation of small molecular interactions by the differences of separate total energies. Some procedures with reduced errors," Molecular Physics, vol. 19, n 4, pp. 553-566, 1970.

[27] R. A. Yossa Kamsi, G. W. Ejuh, Y. Tadjouteu Assatse, C. A. Njeumen, F. Tchoffo et J. M. B. Ndjaka, "Computational study of reactivity and solubility of Rubescin $D$ and $E$ molecules in gas phase and in solvent media using Hartree-Fock and DFT methods," Chinese Journal of Physics, vol. 60, pp. 1-11, 2019.

[28] A. V. Marenich, C. J. Cramer et D. G. Truhlar, «Universal solvation model based on solute electron density and on a continuum model of the solvent defined by the bulk dielectric constant and atomic surface tensions," Physical Chemistry, vol. 113, n 18, pp. 6378-6396, 2009. 
[29] G. W. Ejuh, S. Nouemo, F. Tchangnwa Nya et J. M. B. Ndjaka, «Computational determination of the electronic and nonlinear optical properties of the molecules 2-(4-aminophenyl) quinoline, 4-(4-aminophenyl) quinoline, anthracene, anthraquinone and phenanthrene," Materials Letters, vol. 178, pp. 221-226, 2016.

[30] J. B. Fankam Fankam, G. W. Ejuh, F. Tchangnwa Nya et J. M. B. Ndjaka, "Study of Electronic Structure, Optoelectronics, Linear and Nonlinear Optical Properties and chemical descriptors of Dibromodinitrofluorescein Isomers in Gas Phase and Solvent media Using Ab Initio and DFT methods, " Chinese Journal of Physics, vol. 66, pp. 461-473, 2020.

[31] N. M. O'Boyle, A. L. Tenderholt et K. M. Langner, «Cclib: a library for package-independent computational chemistry algorithms, „ Journal of computational chemistry, vol. 29, $n^{\circ} 5$, pp. 839-845, 2008.

[32] Y. Tadjouteu Assatse, G. W. Ejuh, F. Tchoffo et J. M. B. Ndjaka, «DFT studies of nanomaterials designed by the functionalization of modified carboxylated carbon nanotubes with biguanide derivatives for nanomedical, nonlinear and electronic applications," Chinese Journal of Physics, vol. 58, pp. 253-262, 2019.

[33] R. G. Parr, L. Szentpaly et S. Liu, «Electrophilicity index,» Journal of the American Chemical Society, vol. 121, n 9, pp. 1922-1924, 1999.

[34] Y. Ye, G. Tang, Y. Han, L. F. Culnane, J. Zhao et Y. Zhang, "DFT studies on the vibrational and electronic spectra of acetylsalicylic acid,» Optics and Spectroscopy, vol. 120, n 5, pp. 680-689, 2016.

[35] M. V. Veloso, A. G. Souza Filho, J. Mendes Filho, S. B. Fagan et R. Mota, «Ab initio study of covalently functionalized carbon nanotubes, „ Chemical physics letters, vol. 430, $n^{\circ} 1-3, \mathrm{pp} .71-$ 74, 2006.

[36] A. Favila, M. Gallo et D. Glossman-Mitnik, «CHIH-DFT determination of the molecular structure infrared spectra, UV spectra and chemical reactivity of three antitubercular compounds: Rifampicin, Isoniazid and Pyrazinamide,» Journal of Molecular Modeling, vol. 13, n 4, pp. 505$518,2007$.

[37] M. Karabacak, E. Kose et M. Kurt, «FT-Raman, FT-IR spectra and DFT calculations on monomeric and dimeric structures of 5-fluoro-and 5-chloro-salicylic acid,» Journal of Raman Spectroscopy, vol. 41, n 9, pp. 1085-1097, 2010.

[38] M. Ibrahim, A. Nada et D. E. Kamal, «Density functional theory and FTIR spectroscopic study of carboxyl group,» India journal of Pure and Applied Physics, vol. 43, pp. 911-917, 2005.

[39] M. Karabacak et M. Kurt, «The spectroscopic (FT-IR and FT-Raman) and theoretical studies of 5bromo-salicylic acid,» Journal of Molecular Structure, vol. 919, n 1-3, pp. 215-222, 2009.

[40] J. B. Foresman et E. Frish, Exploring chemistry with electronic structure structure methods, Pittsburg, USA: Gaussian Inc., 1996.

[41] Y. Tadjouteu Assatse, G. W. Ejuh, F. Tchoffo et J. M. B. Ndjaka, «Computational Studies on the Molecule 1-(2-Hydroxyethyl)-5-Fluorouracil in Gas Phase and Aqueous Solution and Prediction 
of Its Confinement inside Capped Nanotubes," Advances in Condensed Matter Physics, vol. 2019, pp. 1-14, 2019.

[42] A. Zafar et J. Reynisson, "Hydration free energy as a molecular descriptor in drug design: a feasibility study,» Molecular informatics, vol. 35, n 5, pp. 207-214, 2016.

[43] M. Arivazhagan et J. S. Kumar, «Vibrational assignment, HOMO-LUMO, first-hyperpolarizability and Mulliken's charge analysis of 2, 7-dinitrofluorene,» India Journal of Pure Applied Physics, vol. 50, pp. 363-373, 2012.

[44] M. K. Shukla et J. Leszczynski, «A density functional theory study on the effect of shape and size on the ionization potential and electron affinity of different carbon nanostructures,» Chemical physics letters, vol. 428, n 4-6, pp. 317-320, 2006.

[45] F. Kayadibi, S. Sagdinc et S. Zor, «Theoretical and Experimental Study of the Acid Corrosion Inhibition of Copper by Aspirin (Acetylsalicylic Acid)," Protection of Metals and Physical Chemistry of Surfaces, vol. 56, pp. 202-213, 2020.

[46] E. E. Ebenso, D. A. Isabirye et N. O. Eddy, «Adsorption and quantum chemical studies on the inhibition potentials of some thiosemicarbazides for the corrosion of mild steel in acidic medium, » International journal of molecular sciences, vol. 11, p. 2473, 2010.

[47] R. A. Yossa Kamsi, G. W. Ejuh, P. Mkounga et J. M. B. Ndjaka, «Study of the molecular structure, electronic and chemical properties of Rubescin D molecule," Chinese Journal of Physics, vol. 63, pp. 104-121, 2020. 


\section{Figures}

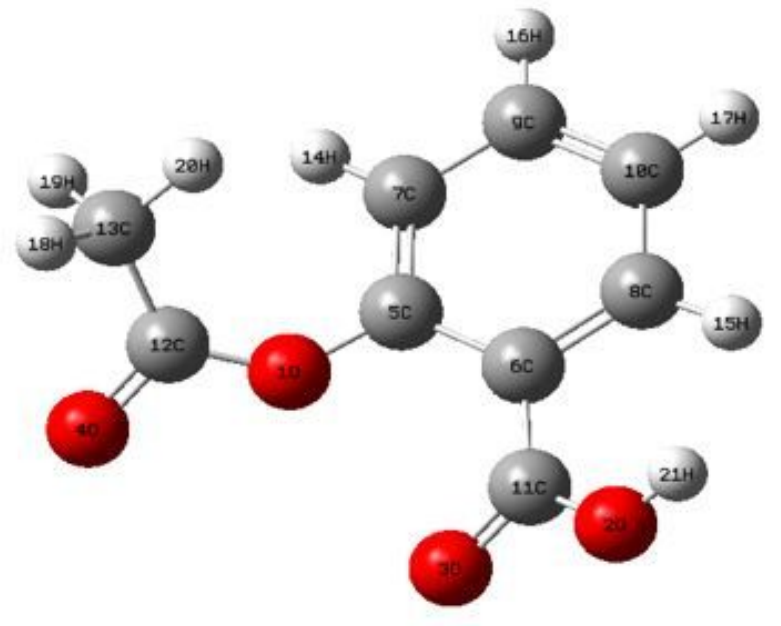

(a) Acetylsalicylic acid

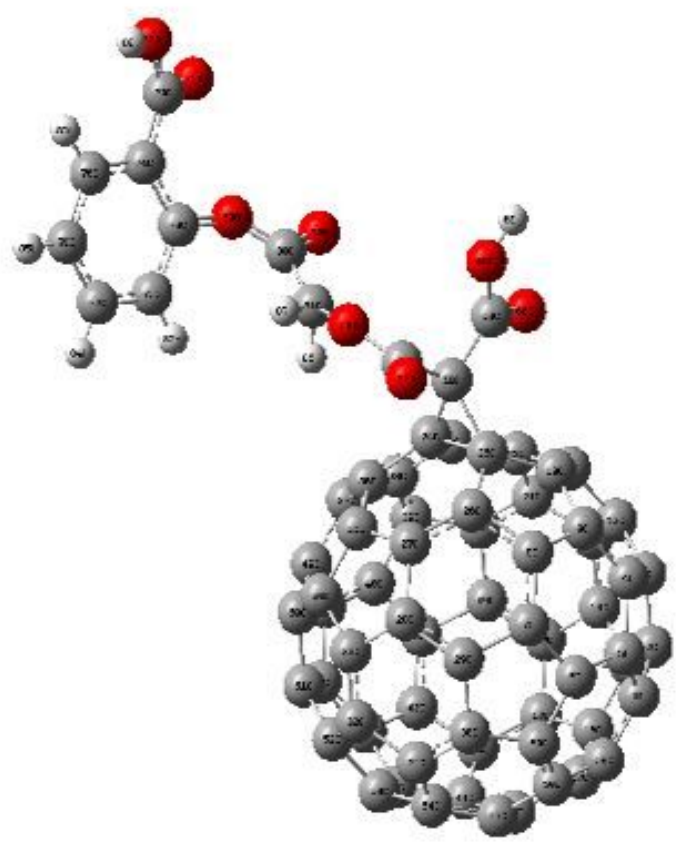

(c) Nanostructure A

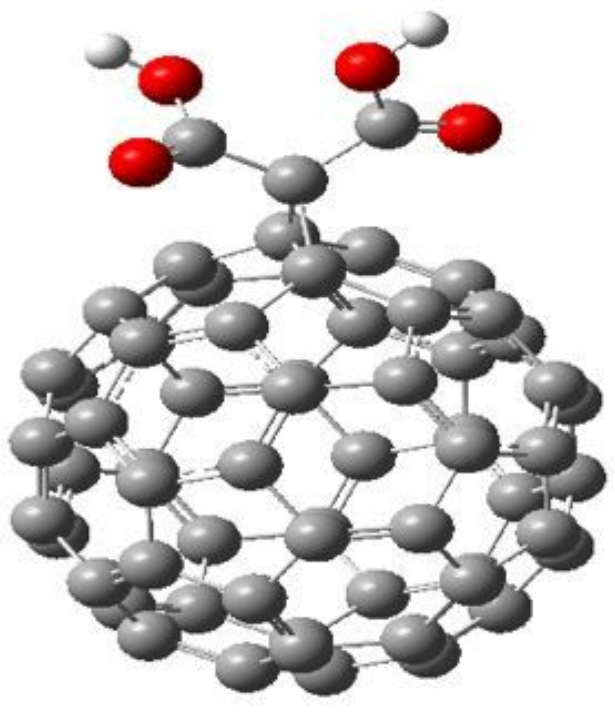

(b) Fullerene ylide

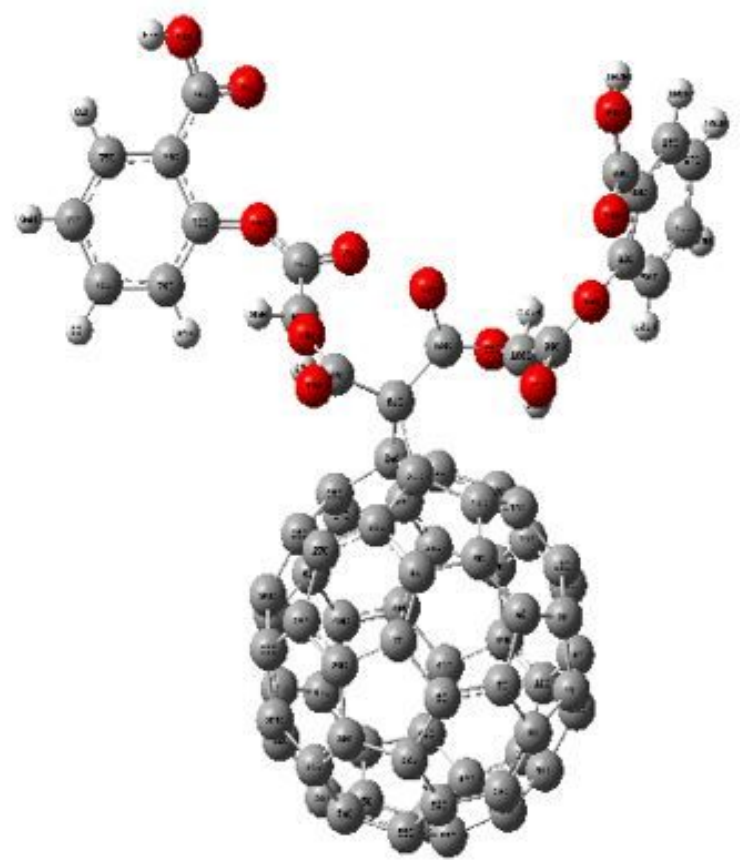

(d) Nanostructure B

\section{Figure 1}

Optimized geometries of (a) Acetylsalicylic acid (ASA), (oxygen atoms are colored red, carbon grey, and hydrogen white); (b) FULL(C60)fC3H2O4 (Fullerene ylide) ; (c) FULL(C60)fC3HO4-C9H7O4 (nanostructure A) ; and (d) FULL(C60)fC304-C18H1408 (nanostructure B) in gas phase. 

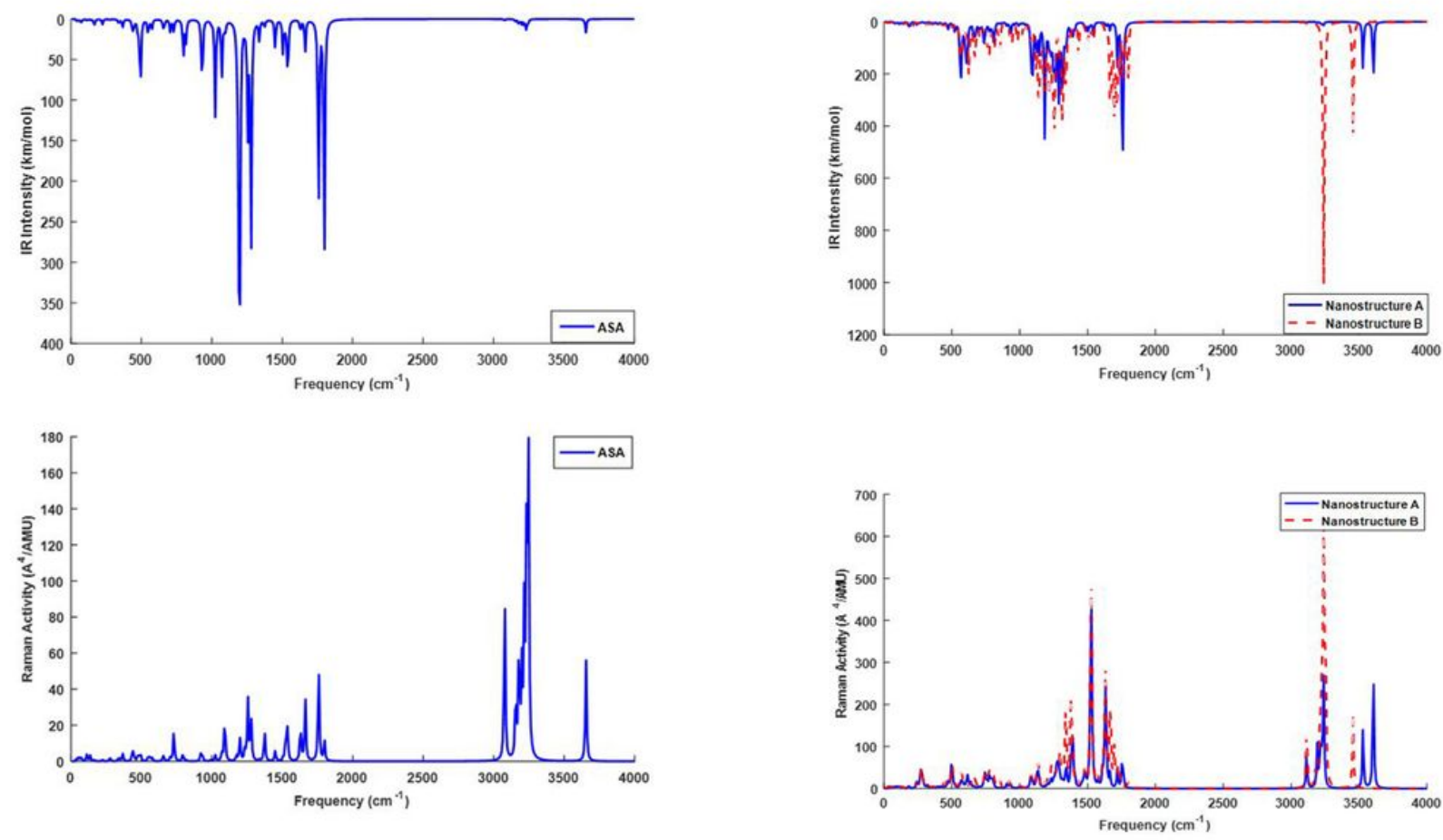

Figure 2

Vibrational IR and Raman spectra of the molecules of acetylsalicylic acid, nanostructures A and B.
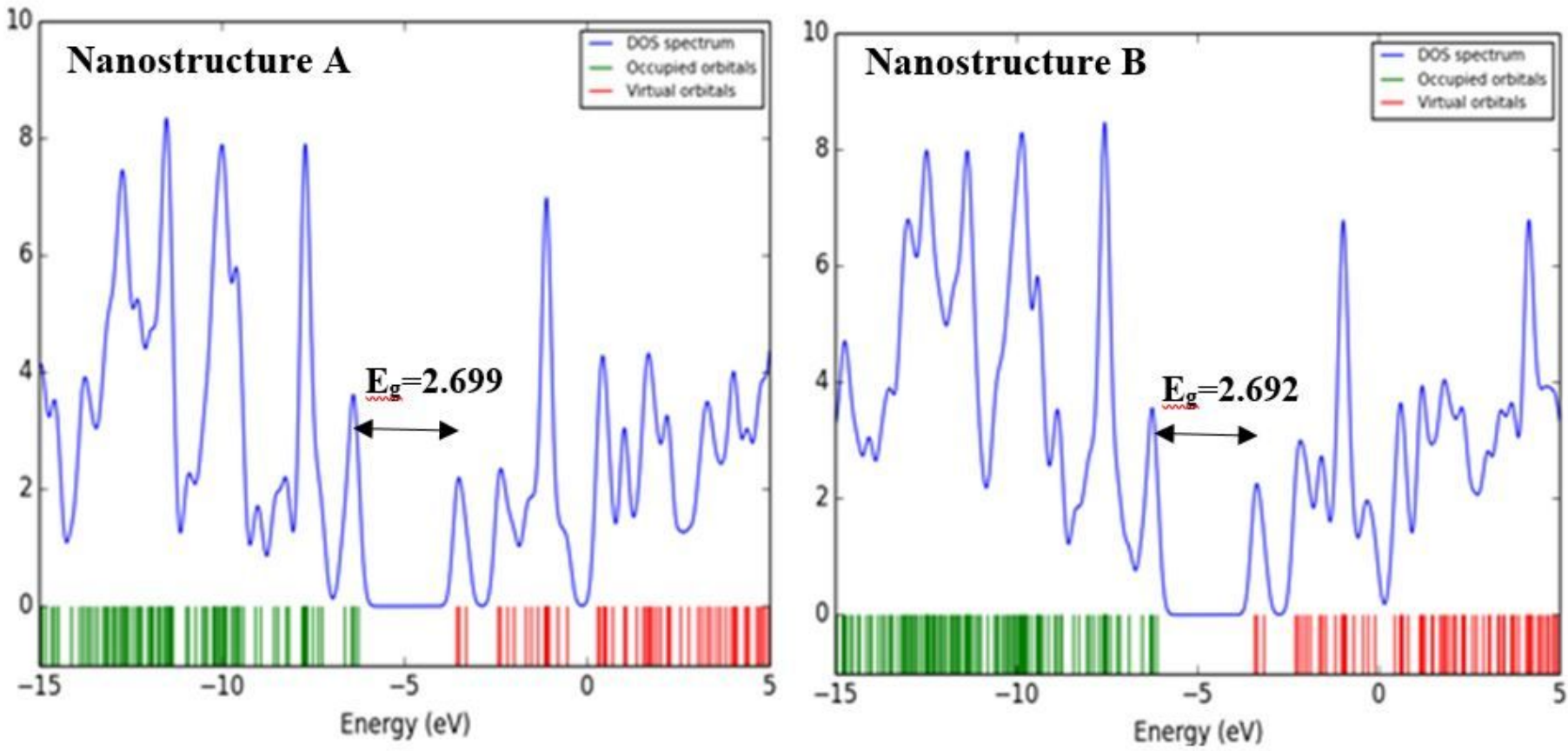

Figure 3

Densities of states of the studied nanostructures in gas phase. 

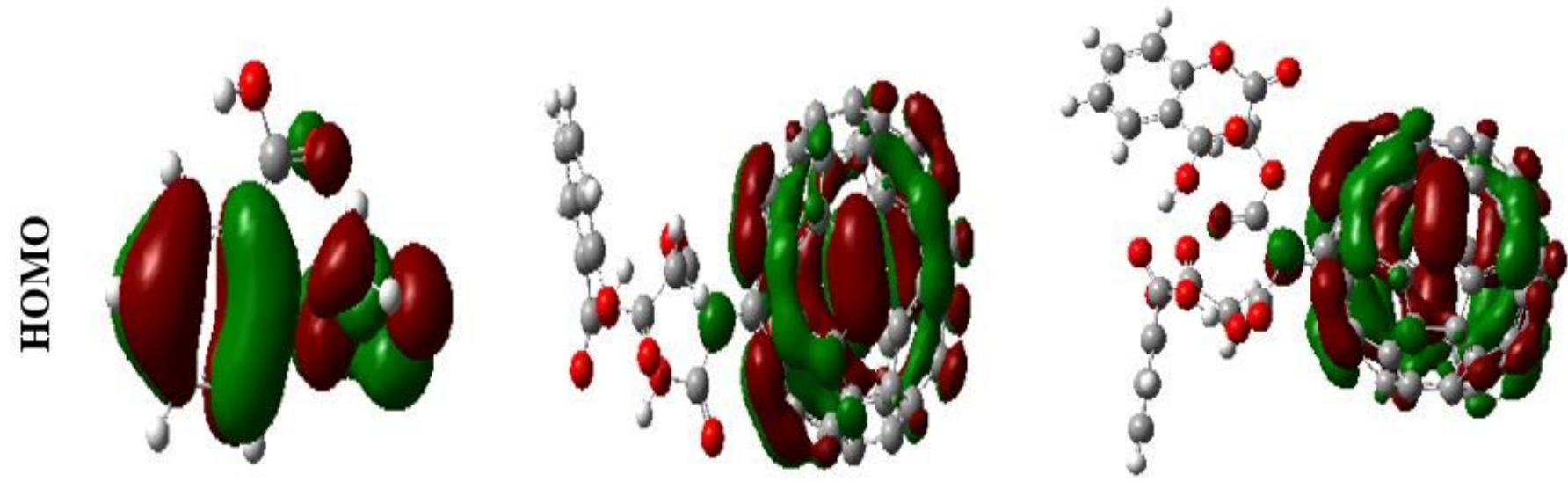

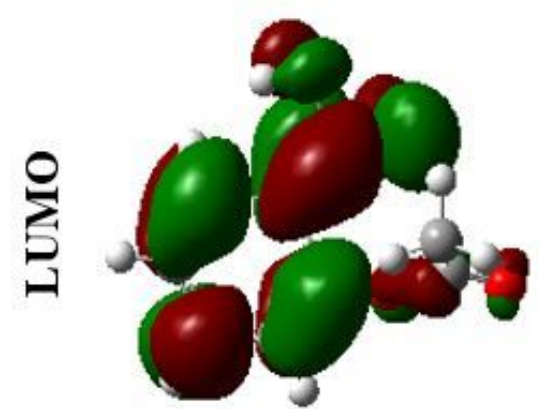

ASA

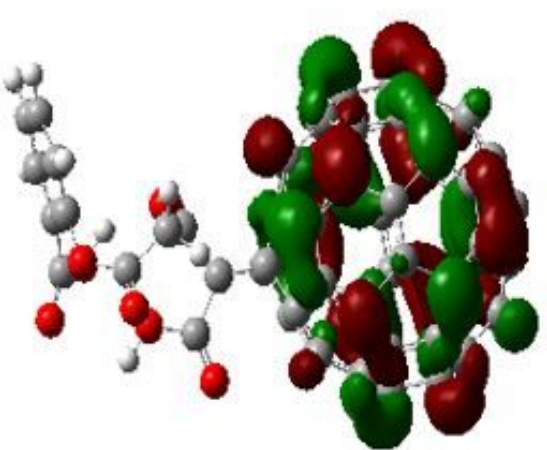

Nanostructure A

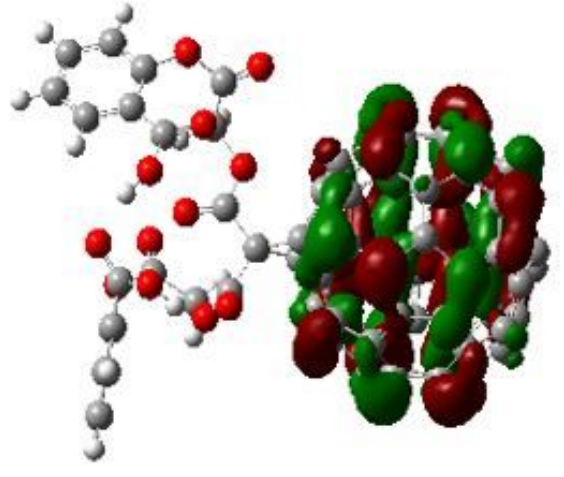

Nanostructure B

Figure 4

HOMO and LUMO molecular orbital diagrams of the studied molecular structures. 


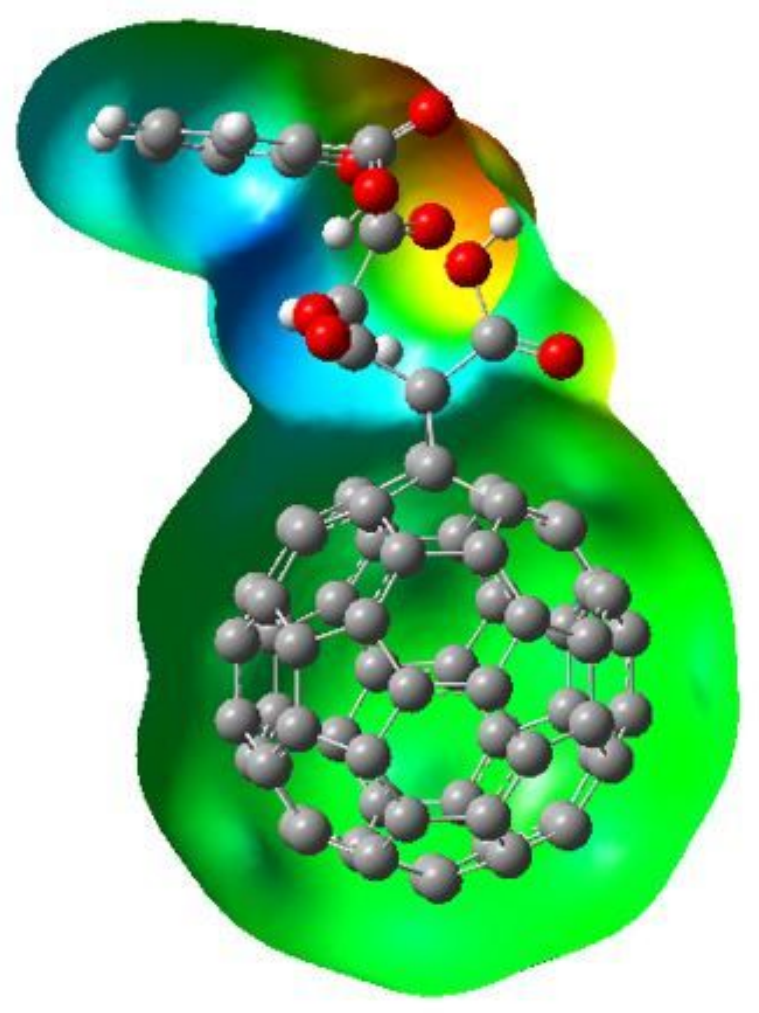

Nanostructure A

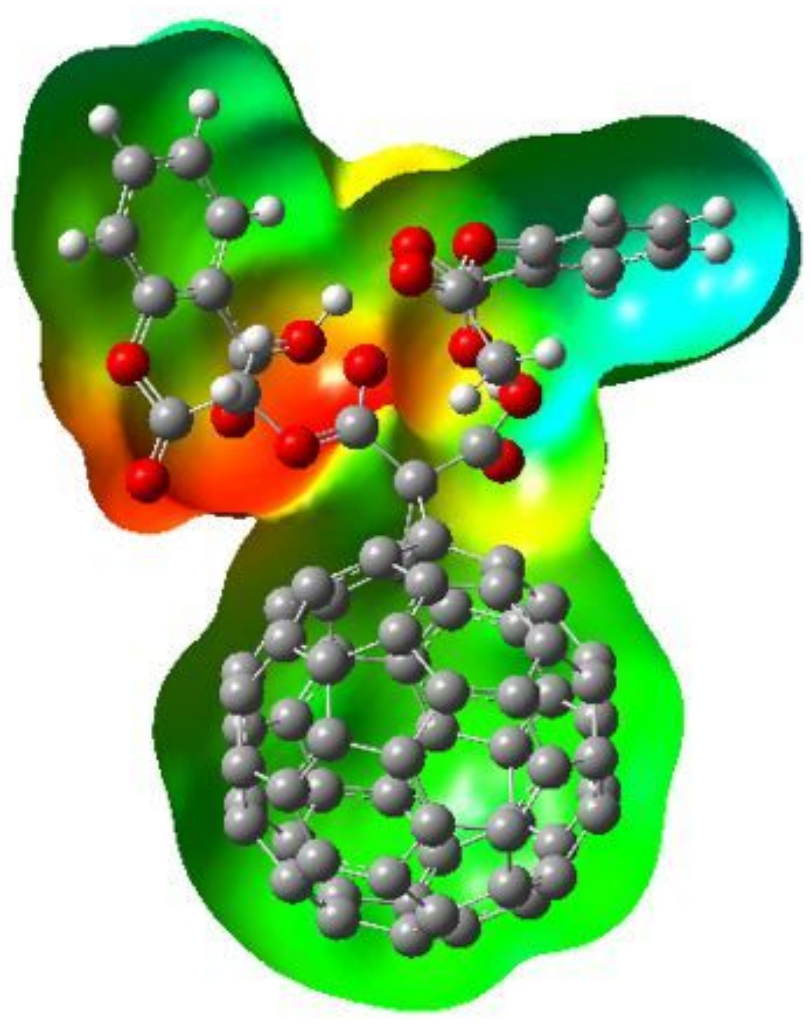

Nanostructure B

Figure 5

Total electron densities mapped with electrostatic potential of modeled nanostructures 